\title{
Hamlet como ironía dominada. Una lectura desde Kierkegaard y el Bildungsroman
}

\section{Hamlet as Controlled Irony. A Reading from Kierkegaard and the Bildungsroman}

\author{
Luis Guerrero Martínez \\ Universidad Iberoamericana, México \\ luis.guerrero@ibero.mx
}

Shakespeare no ha sido igualado -a pesar de los progresos que puede hacer el mundo. Siempre hay algo que aprender de él, y mientras más se lo lee, más se aprende.

\section{KierkegaARd (SKS 6, 419) ${ }^{1}$}

Los más dignos discípulos de Hamlet son $\mathrm{Ni}$ etzsche y Kierkegaard, también libres artistas de sí mismos.

Harold Bloom $(2011,58)$

\footnotetext{
${ }^{1}$ Las referencias a las obras de Kierkegaard se hacen de la última edición de las obras completas en danés Søren Kierkegaard Skrifter (SKS 1997-2013), indicando el número de volumen y la página. Esta referencia está incluida en las últimas traducciones académicas de Kierkegaard al español. Para Hamlet uso las referencias canónicas.
} 
Resumen: Con el fin de explorar los aportes de Kierkegaard a la teoría literaria en conexión con la filosofía, este estudio aborda dos cuestiones: el modo específico como Goethe introduce en Los años de aprendizaje de Wilhelm Meister el drama shakesperiano Hamlet, como una forma paradigmática del Bildungsroman. Este antecedente permite valorar la propuesta de Kierkegaard sobre lo que denominó "ironía dominada", en la cual Shakespeare tiene también un papel relevante. Mi objetivo es hacer una lectura de Hamlet, no exhaustiva pero sí detallada, desde los rasgos más específicos de la ironía kierkegaardiana.

Palabras clave: Hamlet, ironía, Bildungsroman, Goethe, Kierkegaard.

Abstract: In order to explore Kierkegaard's contributions to literary theory in connection with philosophy, this study addresses two issues: how Goethe introduces Wilhelm Meister's Apprenticeship into the Shakespearean drama Hamlet, as a paradigmatic form of the Bildungsroman. This background allows us to assess Kierkegaard's proposal on what he called "Irony as a Controlled Element" in which Shakespeare also plays an important role. My objective is to present a reading of Hamlet, not exhaustive but detailed, from the most specific features of the Kierkegaardian irony.

Keywords: Hamlet, Irony, Bildungsroman, Goethe, Kierkegaard.

Recibido: 23 de abril de 2019

Aceptado: 18 de agosto de 2019 https://dx.doi.org/10.15174/rv.vi25.458 


\section{La importancia de Shakespeare en el Bildungsroman}

$\mathrm{E}$ n los Fragmentos del Lyceum de 1797, Friedrich Schlegel afirmó que "las novelas son los diálogos socráticos de nuestro tiempo. En esta forma liberal ha buscado refugio la sabiduría de la vida huyendo de la sabiduría de la escuela” (Schlegel, 2009: 30). De este modo provocativo, el principal representante del movimiento romántico de Jena, hacía sonar el toque de guerra contra el modo de concebir el saber, la sociedad y la vida misma, los cuales, a su entender, estaban aprisionados bajo los parámetros ilustrados y racionales que pretendían dominar la cultura de su época.

La referencia a Sócrates en el texto citado tiene una significación especial, pues remarca la interpretación que hicieron los románticos de la ironía socrática como forma de hacer frente a las falsas apariencias. Desde su propia ignorancia Sócrates reducía al absurdo reiteradamente los argumentos que sus oponentes consideraban verdaderos. ${ }^{2}$ La ironía consiste en el contrasentido de que quien afirma no saber (Sócrates), pone al descubierto el falso saber, reduciéndolo al absurdo. La diferencia con la postura socrática también aparece en el fragmento de Schlegel, pues no se trata de contraponer el "saber" contra el "falso saber", sino la "sabiduría de la vida" contra la "sabiduría de escuela". Este es otro aspecto clave del movimiento romántico: la búsqueda de un genuino modo de vida contra los estereotipos sociales que ahogan de mil formas la subjetividad. Como afirma Binetti, "esta novela no celebra grandes

${ }^{2}$ Como ejemplo de esta ironía Socrática puede recordarse, la afirmación de Menón después de que, en tres ocasiones, sus argumentos para definir la virtud fueron reducidos al absurdo por Sócrates: "En verdad, estoy entorpecido de alma y de boca, y no sé qué responderte. Sin embargo, miles de veces he pronunciado innumerables discursos sobre la virtud, también delante de muchas personas, $y$ lo he hecho bien, por lo menos así me parecía. Pero ahora, por el contrario, ni siquiera puedo decir qué es" (Platón: 80a). 
acontecimientos históricos, ni proezas heroicas, ni glorias épicas. Por el contrario, ella descubre el sentido propio de la subjetividad singular, la inmanencia de lo divino en su proceso individualizante" (Binetti, 2015: 52). De esta forma, la ironía no se reduce a la simple negación de todo lo establecido, sino que está acompañada por la aspiración de construir (Bildung) un modo de vida, para lo cual los Bildungsroman ${ }^{3}$ se constituyen en el instrumento paradigmático. Como la filosofía no puede o no quiere hacerse cargo de la riqueza subjetiva de las experiencias y sentimientos, la novela toma ese papel, para lo cual requiere del ejercicio de la libertad estética, y no la sumisión a los parámetros de la filosofía.

En los Fragmentos de 1798, Schlegel afirma que una filosofía de la poesía tendría que fluctuar entre la unión y separación de ambas formas de saber, y "empezar con la autonomía de lo bello, con la proposición de que lo bello está y debe ser separado de lo verdadero y lo moral, y que tiene los mismos derechos que estos" (Schlegel, 2009: 119). Unos años antes Schiller proclamó algo similar al relacionar la libertad con lo lúdico. Para él, la belleza es una consumación de la humanidad, es forma y es vida; sin embargo, la belleza no es mera forma ni mera vida, y cada una de estas realidades plantea sus propias exigencias. "La belleza es el objeto común de ambos impulsos, es decir, del impulso de juego" (Schiller, C. XV, 5). Es gracias al juego que puede haber una relación forma-vida no arbitraria, pero tampoco coaccionada. Se trata, en cierto modo, de una antropología que considera al juego como una acción creativa, bajo sus propias reglas y no necesariamente vinculadas a normas externas ni a una objetividad racional. Esta noción es importante porque así el arte representa una forma autónoma, desinteresada y

${ }^{3}$ Literalmente Bildungsroman significa novela de formación o educación. El término fue acuñado por el filólogo de Magdeburgo Johann Karl Simon Morgenstern. 
elevada de actividad humana, que permite hacer frente a una cultura social empantanada en la utilidad y las reglas establecidas. La teoría estética de Schiller está estrechamente vinculada con su función educativa, con la búsqueda de la perfección humana, al considerar el arte como una manifestación de esta perfección. Para él, como afirma Michael Minden, "el espacio estéticamente protegido permite adivinar una solución al problema de cómo los individuos autónomos pueden unirse en una comunidad estable sin sacrificar su autonomía definitoria” (Minden, 1997: 24).

El referente germánico más importante del Bildungsroman es sin duda la novela de J. W. Goethe, Los años de aprendizaje de Wilhelm Meister, publicada en partes entre 1795-1796; ${ }^{4}$ Schlegel comparó la importancia de esta novela a la Revolución Francesa y a la "doctrina de la ciencia" de Fichte (Schlegel, 2009: 107). Además, esta obra es fundamental para comprender la importancia de Shakespeare, especialmente de su tragedia Hamlet, en la transformación espiritual de su protagonista y, con él, su papel preponderante en el Sturm und Drang y en el Romanticismo.

Los años de aprendizaje de Wilhelm Meister narra la historia de Wilhelm, un joven apasionado espectador del arte escénico. La primera parte de la historia describe su amor por Marianne, una actriz dramática con quien tiene apasionadas relaciones. Esta experiencia amorosa parecía convertirse en el eje que daba sentido a su vida, colmándolo de una profunda alegría. Gracias a ella sentía

${ }^{4}$ Los años de aprendizaje de Wilhelm Meister forma parte del "Ciclo Wilhelm Meister" que consta de tres novelas: Wilhelm Meisterstheatralische Sendung (Misión teatral de Wilhelm Meister), esta novela nunca se publicó y fue encontrada y sacada a luz de los archivos goethianos en 1885. La segunda novela Wilhelm Meisters Lehrjahre (Los años de aprendizaje de Wilhelm Meister) es propiamente el Bildungsroman que tuvo amplia repercusión en el mundo intelectual europeo, y finalmente Wilhelm Meister Wanderjahre (Años de andanzas de Wilhelm Meister) publicada en 1821, con una segunda versión modificada en 1829. 
que podía liberarse de su vida burguesa, monótona y lánguida; con más razón se sentía ajeno a la ocupación comercial que su padre le forzaba a seguir, considerándola como un oficio vil y carente de espíritu. En cambio, en unión de Marianne todo cobraba una nueva y esperanzadora dimensión en sus ocupaciones ordinarias, aficiones y proyectos futuros. Uno de estos proyectos era escribir diversas reflexiones sobre el teatro, el cual había comenzado desde hacía algún tiempo. Sin embargo, esta dicha no duró mucho, Marianne traicionó su amor al fugarse con un comediante. Empieza entonces el declive de Wilhelm: como un sonámbulo que no lleva rumbo fijo, se hundió en el vacío y la melancolía, cedió a los deseos de su padre dedicándose al comercio y se propuso dejar en el olvido su pasión por el arte dramático, quemando - para testimoniar que no habría marcha atrás- sus anotaciones sobre el teatro que con tanto cuidado había realizado.

El destino o el azar tomaron ocasión de un viaje de negocios de Wilhem para dar inicio a la reconstrucción de su propia identidad. En uno de los caminos entró en contacto con un grupo teatral, que estaba a punto de desintegrarse por problemas legales y económicos. Decidió entonces ayudarlos y, aunque sin mucho convencimiento, se fue comprometiendo con aquella compañía teatral. A partir de este encuentro se desarrolla la parte más extensa de la obra, narra la vida ordinaria de un teatro ambulante de aquella época, con muchas historias secundarias que se entrecruzan, historias de amor y egoísmo, de vanidades y celos, de éxitos y fracasos. Hay dos aspectos de Wilhelm, como personaje principal, que dan unidad a todos esos acontecimientos: sus continuas reflexiones sobre el arte dramático y su personalidad bien dispuesta para el desarrollo artístico y humano de la compañía teatral, tarea nada fácil debido a la pobre educación de sus integrantes.

Si bien Wilhelm está marcado por la melancolía de su amor perdido, es gracias al contacto con el arte que, a pesar de todo y 
sin habérselo propuesto, él mismo va construyendo (Bildung) su propia existencia. Ya había preconizado este poder del arte cuando al principio de su relación con la compañía teatral aconsejó a uno de ellos:

El que ha nacido con talento para un arte encuentra en su ejercicio la más bella existencia. Nada hay en el mundo que no implique dificultades. Sólo el impulso interior, la afición, el amor, nos ayudan a sobreponernos a los obstáculos, allanan los ánimos y nos elevan de la estrecha esfera, donde otros se angustian miserablemente (Goethe, 1968: 662).

Una de sus más importantes transformaciones se realiza al entrar en contacto con las obras de Shakespeare. Es importante referir las circunstancias que marcaron ese primer encuentro, pues muestra el prejuicio y la resistencia inicial de acercarse al escritor inglés, y el convencimiento posterior de su grandeza. Su compañía de teatro fue contratada para hacer varias representaciones en un castillo, con ocasión de la visita de un príncipe a aquel lugar. Ahí conoció Wilhelm a Yarno, un comandante que había estado con embajadas en Francia, Inglaterra e Italia. En una de sus conversaciones Yarno le preguntó a Wilhelm:

- ¿Ha leído usted alguna vez una obra de Shakespeare?

— No — repuso Wilhelm—, todo lo que oí decir de esas obras no me produjo curiosidad de conocer más directamente a ese monstruo extrańo, que parece transgredir las barreras de la verosimilitud y el decoro.

- Sin embargo, contestó Yarno, le aconsejaría a usted que hiciera la prueba; no puede perjudicarnos en nada el ver lo singular con nuestros propios ojos. Le prestaré algunas, y no podrá usted emplear de mejor modo su tiempo que desprendiéndose al ins- 
tante de toda otra cosa y viendo este desconocido mundo con esa linterna mágica en la soledad de su vieja morada. Sólo una sola cosa le pongo como condición: que no se deje repeler por la forma; en cuanto a lo demás, puedo fiarme de su recta sensibilidad (Goethe, 1968: 729).

En este estado de ánimo recibió y leyó las obras del dramaturgo inglés, y en poco tiempo se apoderó de Wilhelm el torrente de ese genio enorme y lo arrebató hacia un mar inmenso, donde muy pronto se sumergió, olvidando todo lo demás. Conforme leía, fueron apareciendo en él un sinnúmero de sensaciones, las cuales nunca había siquiera sospechado que existieran. Nada ni nadie podía sacarlo de esa profunda conmoción. Fue entonces que Wilhelm, en una nueva conversación con Yarno, pudo realizar la siguiente valoración de las obras de Shakespeare:

No recuerdo que ningún libro, ninguna persona, ningún otro acontecimiento de la vida haya producido tanta impresión como estas obras exquisitas. Parecen ser obra de un genio celestial que se llega a los hombres para dárselas a conocer del modo más benigno. Son más que obras poéticas. En ellos encontramos abiertos los inmensos libros del destino, en los que braman los vientos tempestuosos de las más agitadas existencias, y con toda celeridad y violencia dan vuelta a sus hojas. Estoy tan asombrado y fuera de mí ante la fuerza y la ternura, la vehemencia y la serenidad de tales obras (Goethe, 1968: 736).

Con la lectura de Shakespeare, Wilhelm experimentó una gran conmoción en lo más profundo de su espíritu; consideraba que muchos de los enigmas acerca de la naturaleza humana, su destino y comportamiento, estaban expuestos y resueltos en sus páginas, pues cada uno de los personajes representaba paradigmas desde los 
cuales era posible observar los resortes que los impulsaban. Buscó ocasión de hablar con Yarno para darle las gracias por la dicha que le había proporcionado con la recomendación y el préstamo de aquel tesoro:

Todos los presentimientos que alguna vez he tenido sobre la humanidad y su destino, que desde niño me han acompańado sin que yo mismo lo notara, los encuentro realizados y desenvueltos en las obras de Shakespeare. [...] Las escasas miradas que he lanzado a su mundo me incitan, más que ninguna otra cosa, a marchar con paso más rápido por el mundo real, a mezclarme en las oleadas del destino que ruedan sobre él, y algún día, si tengo esa fortuna, yo mismo podré llenar algunas copas en el inmenso mar de la verdadera naturaleza, para verterlas desde la escena sobre el sediento público de mi patria (Goethe, 1968: 736).

A partir de estos acontecimientos, Los años de aprendizaje de Wilhelm Meister se centran, casi hasta el final, en la representación de Hamlet por aquella compañía de teatro. Paulatinamente esta obra de Goethe introduce al dramaturgo inglés en cuatro dimensiones: la profunda transformación interior al leer a Shakespeare; la experiencia estética al interpretar los personajes de sus obras o dirigir la puesta en escena de alguna de ellas; la importancia social de traducir a Shakespeare; y finalmente, la distinción que el protagonista establece entre novela y drama. Este encuentro con las obras de Shakespeare es uno de los principales pilares del Bildungsroman, al mostrar el papel estético y formativo de la novela, pues sus valoraciones no están expuestas como un ensayo o un tratado de estética, sino como parte de la trama de Wilhelm Meister. ${ }^{5}$

${ }^{5}$ Minden considera que la forma que logró Goethe al introducir el drama shakesperiano en una novela marcó un sello distintivo para la literatura moder- 


\section{La influencia de Shakespeare en Kierkegaard y su crítica a H. C. Andersen}

$\mathrm{Al}$ igual que Goethe, y muchos otros autores de su época, Kierkegaard constató en la obra de Shakespeare la enorme fuerza poética. Son numerosas las referencias que Kierkegaard tiene del escritor inglés, de sus obras y personajes, en ocasiones para ejemplificar una pasión, una situación o simplemente una imagen; también para ponerlo como ejemplo de escritor, de ironista, de genio y, otras veces, para contrastarlo con la denigrante trivialidad de la masa o simplemente para hacer un panegírico de su grandeza. ${ }^{6}$ Así, por ejemplo, en El diario de un seductor, Juan asocia el nombre de su seducida con un personaje de El rey Lear de Shakespeare (Acto 1 escena 1): “ $¡$ Cordelia! Es realmente un nombre excelente; así se llamaba también la tercera hija de Lear, esa extraordinaria joven cuyo corazón no estaba en sus labios, cuyos labios enmudecían mientras su corazón se ensanchaba. Eso mismo sucedía con mi Cordelia. Se le parece, estoy seguro (SKS 2, 326).

Antes de abordar con más detalle el papel que Kierkegaard otorga a Shakespeare como representante paradigmático de la iro-

na. "Las diferentes características de la novela y los héroes dramáticos se enfrentan unos contra otros. Hamlet y Wilhelm se reflejan mutuamente: Hamlet es un héroe novedoso en el drama, y por lo tanto es pasivo cuando debería estar activo, mientras que Wilhelm, que procesa activamente su propia historia, es un héroe dramático a la deriva de la novela, que generalmente sólo tolera a los protagonistas pasivos" (Minden, 1997: 20).

${ }^{6}$ En su estudio sobre Kierkegaard y Shakespeare, James Ruoff desarrolla la influencia del dramaturgo inglés en Kierkegaard en tres puntos: en algunos aspectos de la vida personal del danés, identificándose con varios personajes de Shakespeare y con el autor mismo; en su psicología, encontrando ejemplos convincentes para ciertas categorías de la existencia, y en su estética, especialmente por medio de su concepto de tragedia (Ruoff 2006). Mi estudio, a diferencia de Ruoff, se centra en su influencia y derivación en el ámbito de la ironía. 
nía dominada, es importante tomar en cuenta sus consideraciones en torno a la crítica literaria contenidas en su escrito De los papeles de alguien que todavía vive. Se trata de una amplia reseña crítica a la novela escrita por su coterráneo Hans Christian Andersen titulada Apenas un músico. Esta crítica sirve como contraste para comprender mejor la valoración que Kierkegaard hará del dramaturgo inglés. Apenas un músico. Novela original en tres partes [Kun en Spillemand. Original Roman i tre Dele] publicada en noviembre de 1837, fue la tercera novela de Andersen, a la que antecedieron El Improvisador (1835) y Yo no (1836). En cierto sentido, las tres tienen un punto en común, la dificultad de sus protagonistas para enfrentar las rígidas divisiones sociales, aunque hay algo que las diferencia. En las dos primeras las cualidades espirituales de los protagonistas les permiten sortear esas dificultades, logrando salir airosos en sus respectivos ambientes; su victoria queda reflejada en el final feliz de ambas narraciones. En cambio, en Apenas un músico esa misma temática es desarrollada bajo una trama pesimista y desoladora.

Apenas un músico nos presenta la historia de Christian, un niño pobre, y Naomi, una nińa judía, adoptada por una familia noble que pertenecía a los mejores grupos sociales. Christian vivió enamorado de Naomi, aunque ambos tomaron caminos separados el resto de sus vidas. Christian buscó refugio en su talento musical y en los sueños por abrirse paso a través del camino artístico; en el fondo ansiaba poder romper las barreras sociales que los separaban. Muy a su pesar no logró el reconocimiento artístico que anhelaba. Y aunque sus caminos se vuelven a cruzar momentáneamente al final de la novela, lo único que los une es la decepción y el vacío de sus vidas. Incluso ella, aunque aparenta una situación exitosa y llena de lujos, es solamente el disfraz de su desdicha interior. La novela termina cuando Naomi, sin ni siquiera saberlo, observa el paso de la carroza fúnebre de Christian. Como puede observar- 
se, esta novela de Andersen parece la antítesis del Bildungsroman, pues en ella la aspiración y el talento artístico, lejos de suponer un fundamento para abrirse paso en la formación de la personalidad y en la concepción de la vida, se convierte en ocasión de frustración y vacío; como lo señala Poul Houe: "En parte, la novela es un fracaso como Bildungsroman, esto se muestra con su protagonista, Christian, que vive toda su vida sin poder expresar su personalidad artística" (Houe, 2016: 121).

De los papeles de alguien que todavía vive. Publicado en contra de su voluntades la primera obra publicada por Kierkegaard. ${ }^{7}$ Aunque los estudiosos de Kierkegaard hacen pocas referencias a ella, comparativamente con otras obras, encierra una problemática de especial relevancia para entender no solamente los parámetros de su crítica literaria sino también el conjunto de su obra, y en especial sus obras seudónimas. La opinión de Kierkegaard sobre la novela de Andersen fue muy negativa, bastante mordaz e irónica. Básicamente se centra en enjuiciarlo por carecer de una concepción de vida. "Una concepción de vida es algo más que un prototipo o una suma de frases ensambladas en virtud de su abstracta adversatividad" (SKS 1, 32). Por eso mismo, considera que el lector de esa obra se verá envuelto en extrańos sentimientos, seguramente muy opuestos a los que el autor quería despertar. Por el contrario, cuando "una novela está provista de una concepción de la vida propiamente dicha, ésta se constituye en su más profunda unidad, le permite conciliar su propio centro de gravedad y le libera de la arbitrariedad y de la futilidad, ya que asegura la presencia de una finalidad a lo largo y a lo ancho de la obra de arte" (SKS1, 37).

${ }^{7}$ Kierkegaard intentó primeramente publicar la reseña en Perseus a cargo de Johan Ludvig Heiberg, pero después de una doble negativa que aludía a su rebuscado estilo; finalmente la publicó como libro en la casa editorial C. A. Reitzel. El texto salió a la luz el 7 de septiembre de 1838. 
En una novela debe poderse encontrar una fuerza espiritual superior que ordene y dé sentido al conjunto, "en Andersen, en cambio, no hay ningún fundamento: cuando el héroe muere Andersen muere con él, arrancando al lector, a lo sumo, un suspiro por ambos como última impresión" (SKS 1, 38). Kierkegaard considera que, en Apenas un músico, su autor muestra un desconocimiento del poder del genio, de su conducta y la forma de luchar; presenta en cambio a un llorica que, contradictoriamente, asegura ser un genio, aunque lo único que tenga en común con él sea sufrir un contratiempo, sucumbiendo al ser arrastrado por las circunstancias. Kierkegaard no duda en afirmar que Andersen, al carecer de un profundo y real sentido de la vida, "se ve obligado a buscar la razón de la aniquilación de sus individuos en el mundo de su propia descreencia del mundo" (SKS 1, 43). ${ }^{8}$

Como se ha mencionado, la opinión de Kierkegaard respecto a Shakespeare fue muy diferente de la que tuvo respecto a Andersen.? En O lo uno o lo otro, específicamente en los Diapsálmata el "esteta A" afirma: "Mi alma retorna siempre al Antiguo Testamento y a Shakespeare. Ahí se siente al menos que los que hablan son seres humanos; ahí se odia, se ama, se asesina a los enemigos, se condena

${ }^{8}$ Andersen, indignado por la crítica de Kierkegaard, buscó ridiculizarlo en el vodevil Una comedia al aire libre. Vodevil en un acto basado en la vieja comedia "El actor en contra de su voluntad". En esta obra se alude a Kierkegaard en la imagen de un peluquero melancólico y parlanchín que busca en la filosofía hegeliana respuesta a su situación, aunque no logre comprenderla. La obra se presentó en el Teatro Real, inaugurándose en mayo de 1840 . Kierkegaard preparó una respuesta que nunca publicó, titulada ¡Un momento señor Andersen!”, en donde, entre otras cosas afirma: "yo jamás me he hecho pasar por un hegeliano, y en este sentido es una necedad de su parte tomar frases de mi pequeña obra para ponerlas en boca de un hegeliano" (Kierkegaard, 2016: 58).

9 Para ahondar en este contraste puede verse el estudio de Richard Summers, "Controlled Irony and the Emergence of the Self in Kierkegaard's Disertation" (Summers, 2001: 303). 
a la propia descendencia y a toda la estirpe; ahí se peca” (SKS 2, 36). Estas consideraciones son un testimonio de los lamentos del propio Kierkegaard respecto a su época, como lo evidenciará en 1846, en otra de sus reseñas literarias: La época presente, ${ }^{10}$ donde compara la época revolucionaria con la suya propia y la situación cultural danesa. En la época revolucionaria se podía respirar ideas por las cuales creer, así como compromiso y pasión por esas ideas: lucha y riesgo en favor de ellas. Era una época de mártires y héroes. "El individuo ya no pertenece a Dios, ni a sí mismo, ni a su amada, ni a su arte, ni a su ciencia; no, tal como un peón pertenece a una hacienda, así el individuo sabe que está perteneciendo a una abstracción, en el que la reflexión lo subordina" (SKS 8, 82). En cambio, la época moderna realiza una proeza dialéctica pues, en lugar de culminar en una rebelión, reduce la realidad interna de todas las relaciones a una simple tensión reflexiva que deja todo en pie, pero hace que toda la vida sea ambigua. La época está sumida en una apática indolencia, ha perdido la pasión, mantiene el orden social, pero vaciándolo de sentido. La individualidad se ha diluido en la masa, en una forma asfixiante de nivelación, donde el cálculo y la reflexión son el impulso de sus vidas aburguesadas, donde el mal es el mal social, perdiendo la noción profunda de pecado. Es una época que ha empoderado a los medios masivos de comunicación para su propia perdición. Para que todo se reduzca al mismo nivel, primero es necesario procurar un fantasma, una

${ }^{10}$ Una reseña literaria de "Dos Épocas", publicada por Kierkegaard en 1846. Como su nombre lo indica, es una reseña de la novela Dos Épocas escrita por Thomasine Gyllembourg, madre de Johan Ludvig Heiberg. Mediante la historia de dos generaciones de una familia en Copenhague, la novela contrasta el periodo del Romanticismo y de Napoleón con el de la Restauración. "Kierkegaard aprovecha la novela para desarrollar algunas de sus ideas sobre la sociedad. Los investigadores suelen catalogar este trabajo como la declaración del pensamiento socio-político más importante de Kierkegaard" (Stewart, 2017: 182). 
abstracción monstruosa, un espejismo que en el fondo no es nada, y ese fantasma es el público. "La época presente es La genealogía de la moral de Kierkegaard. El fundamento de la realidad moderna es la envidia, y ésta engendra nivelación. Así, la nivelación es obra de la nueva realidad dominante: el público. El público, poseído por la envidia, utiliza la prensa como herramienta. La prensa no es responsable ante nadie, por lo tanto, es abstracta y sirve a fines abstractos" (Poole, 1993: 229). La época de los héroes ha pasado, por eso el seudónimo kierkegaardiano busca en Shakespeare un Norte en el océano revuelto de su época.

\section{Hamlet como paradigma estético de la ironía dominada}

Surgida de esa crítica social y aunada a la crítica literaria hacia el Romanticismo, se encuentra otra de las importantes referencias de Kierkegaard a Shakespeare, se trata de su disertación universitaria Sobre el concepto de la ironia. ${ }^{11}$ En este estudio Kierkegaard muestra la importancia histórica que jugó la ironía socrática en el helenismo, y proyecta esa relevancia a distintos momentos de inflexión histórica. Gracias a la ironía, una determinada realidad social que ha perdido validez para una época se muestra a sí misma en su imperfección; el primer gran ejemplo de esta ironía fue la socrática: por medio de su proceder inquisitivo lograba que sus interlocutores percibieran las contradicciones de sus discursos. En Sobre el concepto de la ironía, Kierkegaard establece su propia postura sobre el debate en torno a la ironía que se había establecido entre el

${ }^{11}$ Sobre el concepto de la ironía, en constante referencia a Sócrates fue publicada en septiembre de 1841, unas semanas antes de la defensa oficial en la Universidad de Copenhague, una década después de haber iniciado sus estudios universitarios. 
movimiento romántico y el pensamiento de Hegel. ${ }^{12}$ Kierkegaard concluye que no cualquier ironía cumple con la finalidad y justeza de la ironía socrática; de la misma manera, no cualquier ironía en la creación artística logra asumir su verdadero sentido. Es en este punto donde Kierkegaard pone como ejemplo a Shakespeare.

El último apartado de Sobre el concepto de la ironía se titula: "La ironía como momento dominado. La verdad de la ironía”. Se trata de una conclusión o derivación de su tesis sobre la ironía aplicada a la creación artística y a la vida. El "momento dominado" (behersketmomment) de la ironía se refiere al adecuado juego de la subjetividad y la objetividad por medio de la ironía. ¿Qué significa esto? Hegel acusó a los románticos de una exagerada subjetividad, por medio de la cual los ironistas juegan con todo y todo lo reducen a nada "todas las determinaciones que se forman acerca de lo recto y de lo bueno, las destruyen de nuevo. Pueden fingirlo todo: pero dan solamente pruebas de vanidad, de hipocresía y de insolencia. La ironía conoce su maestría sobre todo contenido; no toma en serio nada y juega con todas las formas" (Hegel, 1985: 482). Aunque su juicio es demasiado drástico y muy generalizado hacia el movimiento romántico, Kierkegaard coincide con el filósofo alemán en criticar la ironía cuando ésta ha perdido todo contacto con la objetividad. La verdad de la ironía (ironienssandhed) se refiere a que debe haber, objetivamente hablando, una realidad que ha perdido su validez; por tanto, esta realidad caduca debe ser desplazada con la ayuda de la ironía. Por el contrario, la ironía pierde su validez al transformarse en un movimiento o forma destructora que, subjetiva e indiscriminadamente, es aplicada a cualquier tipo de realidad.

12 Puede consultarse, entre otros estudios, The Anti-Romantic. Hegel Against Ironic Romanticism (Reid, 2014), The Isolated Self: Irony as Truth and Untruth in Soren Kierkegaard's on the Concept of Irony (Soderquist, 2013) y Romantic Irony (Garber, 1988). 
Cuando una obra artística refleja objetividad nos encontramos entonces con la ironía como momento dominado. Para Kierkegaard, esto sucede con frecuencia en las obras de Shakespeare.

Muchas veces se ha ensalzado a Shakespeare como el gran maestro de la ironía, y no cabe duda alguna de que tiene derecho a ello. Shakespeare, sin embargo, jamás permite que el contenido sustancial se evapore en una sublimación fugitiva y volátil, y si su lírica culmina a menudo en locura, hay en esa locura, a su vez, un extraordinario grado de objetividad. Si Shakespeare se relaciona de manera irónica con su poesía, es justamente para permitir que prevalezca lo objetivo. La ironía está presente en todas partes, homologa cada rasgo particular para que no haya demasiado o muy poco, para que se proporcione el verdadero equilibrio en la relación microcósmica del poema hacia el que gravita el poeta mismo (SKS 1, 352; la traducción es mía).

Si bien Kierkegaard no ahondó en la referencia que hizo de Shakespeare como ironía dominada, ni mencionó alguna de sus obras en concreto, considero que es posible ensayar, con los elementos contenidos ahí, de qué manera embona muy bien ese concepto con la obra del dramaturgo inglés, específicamente con The Tragedy of Hamlet, Prince of Denmark. A continuación, siguiendo algunas de las pautas que estableció Kierkegaard respecto a la ironía, mostraré la forma como Hamlet puede ser leída de esa forma. ${ }^{13}$

Como ya se señaló, uno de los aspectos centrales que el filósofo danés observa en la ironía socrática es su crítica social como un momento de inflexión histórica. No se trata simplemente del rom-

${ }^{13}$ Margreta de Grazia refiere como la ironía y muchos otros usos retóricos del lenguaje eran conocidos y de uso común en la época de Shakespeare (Grazia, 2001: 61). 
pimiento de las normas estéticas, políticas o morales; sino de una forma de desenmascarar, por medio del juego de los recursos de la ironía, aquello que, en realidad, carece de consistencia. En Hamlet se muestra una realidad presa de mentiras e hipocresía, de impiedad y deseo de poder, de traición y ansias de muerte. La entrada del rey Claudius en escena es muy significativa: delante de la corte se lamenta de la muerte de su hermano el rey Hamlet, del luto que siente su corazón y de cómo ha seguido los consejos para tomar a la mujer de su hermano como esposa, "con alegría truncada, con esperanza y con lágrimas en los ojos, júbilo funerario y nupciales endechas, con dolor y placer en igual proporción" (1.2.10-13). ${ }^{14}$ De igual forma, su discurso sobre los peligros bélicos ocasionados por Fortinbras, sobre los deseos de Laertes de regresar a Francia, sobre el cariño que le profesa a su sobrino Hamlet, todo eso parece dicho por un hombre prudente, de buen corazón y digno de portar la corona real; sin embargo, esta primera escena del monarca es contrastante cuando, un poco más adelante, se nos revela su verdadera identidad por medio del espectro del rey Hamlet, cuando muestra que todos los oídos de Dinamarca fueron groseramente engañados con la fabulosa invención del motivo de su muerte, ya que ésta no fue causada por el veneno de una serpiente, como se divulgó, sino por una maquinación, "de este modo, mientras dormía, perdí por la acción de mi hermano, y a un mismo tiempo, mi corona, mi esposa y mi vida" (1.5.74-76).

En Hamlet, la corte en conjunto es presentada como una esponja al servicio del Rey, los demás absorben de buena gana los favores del monarca, y éste, cuando los necesita, los aprieta, exprimiendo todo lo que de ellos requiere, dejándolos enjutos otra vez

${ }^{14}$ Para la traducción de Hamlet me he basado en la versión inglesa Burton Raffel y en las traducciones de Conejero-Talens y la de Inarco Celenio / Leandro Fernández de Moratín, haciendo en la mayoría de las veces mi propia traducción. 
(4.2.12-20). Es en este contexto de apariencias y engaños cuando cobra toda su fuerza la expresión: "algo podrido está en Dinamarca” (1.4.90). En contraste con esta realidad aparece la ironía de Hamlet: bajo el simulacro de una aparente locura, sus palabras y reacciones -análogamente a los diálogos socráticos- perturban la conciencia embotada de hipocresía y maldad. Él, quien ante los demás ha perdido la razón, logra que la irrealidad en la que viven quede de manifiesto, pues "la infamia, aunque toda la tierra la oculte, se descubre al fin a la vista humana” (1.2.257).

$\mathrm{Al}$ analizar Hamlet desde la perspectiva de la ironía, podemos encontrar y distinguir distintos niveles en los que Shakespeare recurre a ella. La más importante es la realizada por el príncipe, en la que se conjugan su melancolía y aparente locura con su gran capacidad en el uso del lenguaje mordaz y cómico, así como a otros recursos de su inventiva; pero también se encuentran las ironías naturales o ironía del mundo, ${ }^{15}$ que no provienen directamente de las acciones o palabras de Hamlet sino en las que un acontecimiento echa por tierra lo que aparentemente era fuerte o se prefiguraba de manera distinta. De esta forma, en Hamlet conviven la personalidad irónica de Hamlet con la ironía que Shakespeare imprime en todo el drama. En este último sentido, la estructura general de Hamlet resulta irónica: el inicio del drama está marcado por las distintas acciones de Claudius por defender su territorio de una posible invasión de Fortinbras: aumenta las guardias, manda

15 Kierkegaard menciona que esta expresión la tomó de Hegel (SKS I, 300), quien afirma en sus Vorlesungenüber die Geschichteder Philosophie que "toda dialéctica hace valer lo que se da directamente por supuesto, pero solamente para hacer que se desarrolle, partiendo de aquí, la desintegración interior: esta ironía podría ser calificada como ironía general del mundo" (Hegel, 1985: 54). Greenblatt considera que la aparente locura de Hamlet fue una forma de sobrevivir hasta que fuera capaz de vengar a su padre, pues sabía que su tío podía acabar con su vida a la primera seńal de amenaza (Greenblatt, 2001: 205) 
fabricar armas sin descanso, envía cartas al rey noruego para que disuada a su sobrino Fortinbras. Sin embargo, a pesar de todos esos esfuerzos, "es irónico que, al final del drama, Fortinbras tenga la última palabra" (Bloom, 1991: 60) y no encuentre ninguna dificultad para ocupar el reino de Dinamarca.

En Sobre el concepto de la ironía Kierkegaard considera que el individuo verdaderamente irónico percibe que la realidad ha perdido su validez, por lo que "se ha salido de las filas de la contemporaneidad y les ha hecho frente" (SKS I, 299). Esta extrańeza del mundo, en el caso de Hamlet, tiene diversas causas: la muerte de su querido padre, el incesto de su madre al poco tiempo de la muerte de su esposo, la revelación del espectro, su deseo de guardar secreto y, sobre todo, la continua experiencia de hipocresía y deshonestidad que observa a su alrededor. Todo esto induce en Hamlet una profunda melancolía. No se trata de una apariencia sino de una manifestación del estado de su alma. Los soliloquios contenidos en la obra, en donde Hamlet puede revelarse a sí mismo, son una importante muestra de este estado de ánimo. En el primero de ellos, antes incluso de tener noticia de la aparición del espectro de su padre, afirma:

¡Oh! ¡Si mi carne demasiado sólida se disolviera, y fundiera su hielo en lluvia de lágrimas. ¡Oh! Si el Dios eterno no hubiera dictado su ley contra el suicidio. ¡Oh, Dios!

¡Oh, Dios! ¡Cuán fatigado estoy ya de todo!

Las cosas del mundo se presentan ante mí vanas, insípidas y estériles (1.2.129-133).

Después, cuando se aparece el espectro y Horatio le dice, presa del temor, que no lo siga, Hamlet contesta: “¿Por qué habría de temerle? No estimo mi vida en absoluto, no más que un alfiler” 
(1.4.66-67). Más adelante, cuando el espectro le pide que no se olvide de él, Hamlet vuelve a manifestar su deseo de romper con el mundo: “¿Acordarme de ti? Sí, yo me acordaré y borraré de mi fantasía todos los recuerdos frívolos, las sentencias de los libros, las ideas e impresiones de lo pasado que la juventud y la observación estamparon en ella, para que solamente tu mandato viva en mi mente sin nada que lo perturbe" (1.5.97-104). También en el célebre soliloquio To be, or no to be Hamlet se lamenta de la existencia:

\author{
Ser o no ser... He ahí el dilema. \\ ¿Qué es mejor para el alma, \\ sufrir insultos de Fortuna, golpes, dardos, \\ o levantarse en armas contra el océano del mal, \\ y oponerse a él y que así cesen? Morir, dormir... \\ Nada más; y decir así que con un sueño \\ damos fin a las llagas del corazón \\ y a todos los males, herencia de carne, \\ y decir: ven, consumación, yo te deseo. \\ Morir, dormir, dormir... (3.1.56-64).
}

Este desapego por el mundo y la propia vida proporcionan una especial libertad para el juego irónico. Kierkegaard lo expresa de la siguiente manera: "En la ironía, el sujeto es negativamente libre, pues falta la realidad que le proveería un contenido; el sujeto es libre de las ataduras con las que la realidad dada retiene al sujeto" (SKS I, 299). A pesar de todos los sufrimientos que recaen en el sujeto irónico, esta libertad le otorga el entusiasmo que surge del mar de posibilidades que se abren ante él para facilitar su tarea de que la inconsistencia de la realidad se desvele. Las posibilidades de su juego irónico son tan amplias como lo son su fuerza imaginativa y los dotes naturales para ese juego. Esto es lo que acontece con Hamlet, a lo largo de la tragedia despliega de muchas formas 
su entusiasmo irónico; el primero de ellos y más importante es la aparente locura que asume después de la aparición del espectro, cuando al hacer jurar a los guardias y a Horatio que guarden silencio termina diciendo: "Quizá en lo sucesivo considere oportuno vestirme de lunática actitud" (1.5.171). ${ }^{16}$ Desde ese momento su enorme ingenio se sirve de la locura para desnudar la personalidad y los vicios que encuentra a su alrededor. A continuación, pondré algunos ejemplos de este ingenio irónico que recorre toda la obra.

En Polonius puede verse con claridad la doble ironía presente en el drama, la de Shakespeare como autor y la de Hamlet como personaje. Al igual que el rey, su primera escena está cargada de aparente sabiduría, cuando aconseja a su hijo Laertes diversos criterios de prudencia en su comportamiento. Sin embargo, muy pronto el personaje muestra su verdadera esencia, la de un maquinador sin escrúpulos, pues como él afirma: "Con el anzuelo de la mentira pescarás la verdad; que así es como nosotros los que tenemos talento y prudencia, solemos conseguir por indirectas el fin directo, usando de artificios y disimulación" (2.1.63-66). Sin embargo, esta doble actitud es contrastada irónicamente con el rebuscamiento de sus diálogos y con la poca eficacia de sus decisiones, hasta hacer de él un personaje cómico, como lo muestra el siguiente parlamento, en donde cree haber descifrado la causa del comportamiento de Hamlet:

Y ahora, mi soberano y vos, señora, querer explicar qué debe ser la majestad de un soberano, las obligaciones de un vasallo, y porque el día es día, noche la noche, y tiempo el tiempo; sería una forma de gastar inútilmente el día, la noche y el tiempo. Así, pues, como

${ }^{16}$ La versión anotada de Hamlet señala que, en la frase "I perchance hereafter shall think meet to put an antic disposition", puede leerse como "pretend to a grotesque / fantastic /clownishmood" (mostrar un humor grotesco / fantástico / bufón) (Raffel, 2003: 185). 
la brevedad es el alma del talento, y que nada hay más enfadoso que los rodeos y perífrasis... Seré muy breve. Vuestro noble hijo está loco; y le llamo loco, pues para definir la locura verdadera, ¿qué otra cosa es la locura, sino estar uno enteramente loco? $(2.2 .85-95)$.

Como puede verse en sus palabras, las cuales tiene que cortar la reina por su tedioso enredo, la personalidad de Polonius es rebajada hasta la hilaridad. La siguiente escena protagonizada por Hamlet y Polonius también está cargada de una graciosa sátira. Hamlet, en su aparente locura, le dice a su interlocutor que es un vendedor de peces. A la negativa de Polonius, el príncipe le contesta: ojalá lo fueras, de esa manera serías honrado, pues "el ser honrado, según va el mundo, es lo mismo que ser escogido uno entre diez mil" (2.2.177-178). A la pregunta de Polonius: ¿Qué estás leyendo? Hamlet contesta: Palabras, palabras, palabras. El consejero insiste en saber qué está leyendo y Hamlet le dice que a un sátiro irrespetuoso que describe a un viejo desagradable; la cual muy bien podría retratar a Polonius. Cuando le pide licencia para irse, el príncipe contesta: "No me puedes pedir cosa que con más gusto te conceda; exceptuando la vida, eso sí, exceptuando la vida" (2.2.220-222). Posteriormente, cuando llegan los cómicos al palacio se presenta otra graciosa situación en la cual Polonius es ridiculizado: Hamlet había pedido a un cómico que recitara el fragmento de un drama que cuenta el asesinato de Príamo a manos de Pirro. El actor fue interrumpido por un comentario de Polonius: "Es muy largo todo esto" (2.2.519); a lo que Hamlet contestó: "Lo mismo dirá de tus barbas el barbero. Tú solamente te entretienes con las jigas y los cuentos de alcahuetes" (2.2.520-522).

El final trágico de Polonius, irónicamente presa de sus torpes maquinaciones, es acompańado nuevamente por el ingenio de $\mathrm{Ha}$ mlet, cuando el airado rey le pregunta dónde está el cadáver de 
Polonius, el príncipe contesta que está en la cena, pero no donde se come sino donde se es comido, entre una numerosa congregación de gusanos, pues el gusano es el monarca supremo de todos los comensales. "Nosotros engordamos a los demás animales para engordarnos, y engordamos para el gusanillo, que nos come después. El rey gordo y el mendigo flaco son dos platos diferentes; pero se sirven en una misma mesa" (4.3.23-27). ${ }^{17}$ Claudius con mayor enfado vuelve a preguntar por el cadáver, y nuevamente Hamlet contesta burlándose del rey y del difunto: "Está en el cielo. Enviad a buscarle. Enviad a alguien para que lo compruebe, y si no está ahí pueden buscarlo en otro sitio. En cualquier caso, si no lo encuentran, en un mes podrán olerlo al subir la galería” (4.3.35-39).

Sin pertenecer a la corte, Rosencrantz y Guildenstern entran en el juego dramático que se establece entre el rey y Hamlet. En ellos termina predominando más la autoridad del monarca que la amistad hacia el compańero de estudios. Tanto Polonius como ellos representan el intento fallido de descubrir el interior del príncipe, la verdadera causa de sus males. Sin embargo, sus dos amigos son presa fácil del ingenio irónico de Hamlet, una de las escenas más ilustrativas de este ingenio es su encuentro después de la representación de los actores, cuando el príncipe le pregunta a Guildenstern si sabe tocar la flauta, a lo que su amigo responde que no; como si se tratara de una incoherencia causada por su locura, Hamlet le insiste en que toque la flauta. Nuevamente su amigo insiste en que no sabe y no puede tocar la flauta, a lo que finalmente Hamlet contesta:

${ }^{17}$ Comentando esta escena, Siddhartha Bose afirma que "se hace visible la relación entre la burla y la celebración irónica de la democracia por medio de la muerte" (Bose, 2015: 172). 
En qué opinión tan baja me tienes. Tú quieres interpretarme, presumes conocer mis registros, pretendes extraer lo más íntimo de mis secretos, quieres hacer que suene desde el más grave al más agudo de mis tonos. Sin embargo, habiendo más música y armonía en esta flauta, tú no la puedes hacer sonar. ¿¿Soy más fácil de tocar que a una flauta? Pues, aunque te parezca yo un instrumento cualquiera que pretendes tañer, jamás conseguirás hacerle producir el menor sonido (3.2.366-376).

La tragedia que los envuelve al final del drama es producto de su vil sumisión a los deseos asesinos del rey, cuando conducen a Hamlet a Inglaterra. Con cierta ironía, Rosencrantz y Guildenstern terminarán siendo emisarios de su propia muerte. Ellos terminan no sabiendo nada, ni los secretos de Hamlet ni el contenido de aquellas cartas.

Así como frecuentemente en el Bildungsroman el ejercicio artístico representado en la obra es ocasión para la formación de la personalidad de los protagonistas, en el caso de Hamlet el arte es ocasión para que la realidad se muestre en su imperfección, este es el movimiento de la ironía dominada al que se refiere Kierkegaard. Hay una escena especialmente importante, la representación de una obra por los comediantes contratados por Rosencrantz y Guildenstern. Ella es ocasión para perturbar profundamente a los reyes, al obligarlos a mirarse en un espejo por medio del drama actuado. Hamlet había pedido a los actores que interpretaran una escena con circunstancias similares al asesinato de su padre y a una reina que prometía fidelidad al amor conyugal, con la convicción de que "quienes son culpables, ante una representación, se sienten heridos en el alma con tal violencia por la astucia de la escena, que terminan confesando sus delitos. Pues el crimen, aun sin lengua, terminará manifestándose por medios prodigiosos (2.2.612-617). 
Cuando la representación comienza a incomodar a los monarcas, y los comentarios del príncipe, cargados de una locuacidad mordaz, crean una fuerte tensión en el ambiente, el rey pregunta el nombre de la obra y si ésta no tiene inconvenientes morales. De forma muy irónica Hamlet responde a su tío:

El nombre de este drama es "La ratonera". ¿Por qué? Es un título metafórico. Esta pieza trata del homicidio de un duque cometido en Viena. (...) ¡Es una perfecta canallada! ¿Pero qué importa? A Vuestra Majestad y a mí, que no tenemos culpado el ánimo, no nos puede incomodar. Al rocín que esté lleno de mataduras le hará dar coces, pero no a nosotros que tenemos los lomos sanos (3.2.238-245).

La similitud del drama golpea fuertemente a la reina. En la representación, antes del asesinato del Duque, su esposa le promete de diversas maneras no volverse a casar si él muriera por algún motivo:

¿No serían traición culpable en mí tales afectos? ¿Yo un nuevo esposo? ¡No! La que se entrega a un segundo señor, mata al primero. [...] Si ya difunto mi primer esposo, contraigo segundas nupcias, que las penas que el ánimo entristecen, todas ellas turben mis deseos y los destruyan, y no encuentre quietud en ninguna parte (3.2.218-225).

Finalmente es representada la escena en la que, para usurparle el cetro, el Duque es envenenado en el jardín. No es de extrańar que el tío de Hamlet se sienta reflejado y detenga encolerizado aquella representación, pues no puede soportar su propia imagen. No es un drama cualquiera el que se representa, es su propio drama. Tanto el rey como la reina son llevados por aquella representación 
a reconocer sus faltas. Poco después, el rey, en la soledad de la plegaria, se dice a sí mismo:

¡Oh! ¡Mi culpa es atroz! Su hedor sube al cielo, llevando consigo la más antigua de las maldiciones, la muerte de un hermano. (...) No puedo pedir perdón de mi crimen, puesto que estoy en posesión de todo lo que me hizo matar: mi corona, mi ambición, mi reina. (...) Pero, ¿qué ha de pasar con quien no puede arrepentirse? ¡Oh! ¡Situación infeliz! ¡Oh! ¡Conciencia ennegrecida con sombras de muerte! ¡Oh! ¡Alma mía aprisionada! Que cuanto más te esfuerzas para ser libre, más quedas oprimida (3.3.37-73).

Después de la representación Hamlet increpa a su madre, haciéndole ver lo injustificable de sus acciones, removiendo lo más oculto de su conciencia, hasta que su madre termina por exclamar: “¡Oh, Hamlet! No digas más. Haces que mis ojos miren hasta el fondo de mi alma, y advierto allí las más negras y arraigadas manchas, que acaso nunca podrán borrarse. [...] No hables más. Tus palabras se clavan como dagas en mis oídos. No más, querido Hamlet. No más" (3.4.86-96).

A pesar del fuerte terremoto interior que experimentan los monarcas, ese malestar no es suficiente para modificar sus intereses. Por el contrario, a partir de este desasosiego el rey determina la muerte de Hamlet, comenzando la parte más trágica de la obra.

En otro de los aspectos propuestos por Kierkegaard, hay dos movimientos cuando se produce una inflexión histórica: debe surgir lo nuevo y lo antiguo debe ser desplazado. A su vez, en este doble movimiento suelen tener un papel diversos agentes: el individuo profético percibe con aún borrosas imágenes lo que traerán los nuevos tiempos. Él no puede hacer valer ese futuro, pero tampoco pertenece a la realidad por la que transita. También está el héroe trágico quien, en su esfuerzo por instaurar un nuevo orden 
de cosas, lucha por aniquilar las columnas que sostienen el régimen caduco. La tarea del individuo irónico, como tercer agente, es lograr que lo antiguo se muestre en toda su imperfección. Él es quien debe abrir juicio contra la imperfección que pretende ahogar la realidad. La ironía "es una locura divina que brama como un Tamerlán y que no deja que quede piedra sobre piedra” (SKS I, 299). Como ya se mencionó, el ironista se ha salido de las filas de la contemporaneidad, se ha vuelto extraño para la realidad que aún tiene dominio sobre los demás. No se siente ligado a esa realidad, y ésta no lo reconoce como suyo. En esta medida, su celo lo convierte en una víctima de la inflexión histórica.

Teniendo en cuenta estas consideraciones del pensador danés, Hamlet puede ser visto como una víctima de la realidad que enjuició. Con cierta clarividencia, al final de su encuentro con el espectro exclamó: "El mundo está fuera de quicio... ¡O suerte maldita! ¡Que haya tenido que nacer yo para enderezarlo!” (1.5.189-190). Los acontecimientos de todo el drama están encaminados al doble extrańamiento entre la realidad y el príncipe. Ya se mencionó la profunda melancolía que padecía y por la que había dejado de tener cualquier tipo de apego por su vida, pero también se ha vuelto insoportablemente incómodo para los demás.

Una vez más para Kierkegaard es importante la similitud con Sócrates, cuya actitud irónica se granjeaba la enemistad de muchos griegos. De entre los diversos ejemplos de esta molestia que provocaba el filósofo ateniense, baste mencionar dos: el de Anito, quien a la postre, sería uno de sus tres acusadores. En el Menón, después de ser ridiculizado por la ironía socrática a base de contraejemplos, Anito se va enojado, no sin antes exclamar: “Ah... Sócrates! Me parece que fácilmente hablas mal de los demás. Yo te aconsejaría, si me quieres hacer caso, que te cuidaras; porque, del mismo modo que en cualquier otra ciudad es fácil hacer mal o bien a los hombres, en ésta lo es en modo muy particular" (Platón: 94e). El otro 
ejemplo es el de Trasímaco en la República, también molesto por el método socrático de refutar y no dar respuestas afirma: “iPor Heracles! Ésta no es sino la habitual ironía de Sócrates, y yo ya predije a los presentes que tú no estarías dispuesto a responder, y que, si alguien te preguntaba algo, harías como que no sabes, o cualquier otra cosa antes que dar una respuesta" (Platón: 337a).

De igual forma puede considerarse a Hamlet como una víctima. Después de la muerte de Polonius, ya con desesperación en sus palabras, el Rey dice a su mujer que debía haber reprimido antes a ese joven loco, pues su "libertad es una amenaza para todos... para mí, para ti misma, para todos y cada uno" (4.1.15-16). Entonces, con una enorme hipocresía, Claudius le pide a Hamlet que se marche a Inglaterra, pues con amor desea su bien; sin embargo, en las cartas que escribió al soberano inglés pedía la pronta muerte de Hamlet, ya que "su vida es para mí una fiebre ardiente, y solamente tú puedes aliviarme. Hazlo así, Inglaterra y hasta que sepa que descargaste el golpe, por más feliz que mi suerte sea, no se restablecerán en mi corazón la tranquilidad, ni la alegría" (4.3.6770). Azarosamente truncada su resolución, el rey concibe una última forma de acabar con la vida de Hamlet, al igual que con su hermano, el veneno sería el medio para asesinarlo.

Incluso antes de morir víctima por el sable envenenado de Laertes y las argucias del monarca, Hamlet ya era víctima de los acontecimientos del castillo de Elsinore desde la muerte de su padre; desde entonces, el príncipe que era querido por el pueblo, que tenía una vida plácida estudiando en Wittenberg, que sabía hacer amigos, se transformó, como se ha señalado, en un extraño y molesto enemigo, de forma que él hubiera preferido quitarse la vida si los impedimentos morales no lo detuvieran. En Los años de aprendizaje de Wilhelm Meister se nos muestra un posible retrato de Hamlet antes de los sombríos acontecimientos. En la novela de Goethe, su protagonista el actor Wilhem, deseoso de interpretar 
adecuadamente el papel de Hamlet, reflexiona acerca de su personalidad:

Busqué todas las huellas en que se manifestara el carácter de Hamlet en tiempos anteriores a la muerte de su padre y lo que habría sido acaso si nada de eso hubiera sucedido. El concepto de lo justo y de la dignidad de príncipe, con la conciencia de la excelsitud de su nacimiento, se desenvolvían en él. [...] Su amor por Ofelia era sólo un secreto presentimiento de dulces necesidades. Reconocía a la gente honrada y sabía apreciar la paz de que goza un ánimo sincero al confiarse al pecho de un amigo; y si algún odio podía germinar en su alma tierna, era el desprecio a cortesanos falsos y tornadizos, jugando con ellos sarcásticamente. Sabía dispensar y olvidar una ofensa; pero jamás podía conciliarse con el que traspasara los límites de lo justo, de lo decoroso y de lo bueno (Goethe, 1968: 749).

Hamlet se convierte en víctima por una doble causa: por la solidez de su carácter moral que le impide acomodar su vida en favor de la deshonestidad, y por la molestia y peligro que ocasiona a los monarcas. Sin embargo, Hamlet no es un héroe, él mismo se reprocha continuamente no tener el valor suficiente para actuar y vengar el asesinato de su padre; por ejemplo, hacia el final del drama, se compara con los soldados del ejército noruego que ve pasar hacia Polonia, quienes se entregarán a terribles peligros y a los golpes de la fortuna entre la vida y la muerte; por su parte, él no es capaz de llevar a cabo la promesa que hizo al espectro de su padre de vengar su muerte, se califica de negligente y de cobarde. "Todos los acontecimientos me acusan y espolean mi torpe venganza [...] ¿Por qué vivo diciendo 'esto es lo que debe de hacerse' cuando me sobran motivos, voluntad, fuerza y medios para ejecutarlo? [...] 
Mi padre asesinado, mi madre deshonrada. ¿Cómo estoy de pie entonces?" (4.4.32-47).

Kierkegaard se refirió a este aspecto de Hamlet en Etapas en el camino de la vida ${ }^{18}$ donde el seudónimo Frater Taciturnus considera que la indecisión de Hamlet lo sitúa, a diferencia del héroe estético que sabe actuar con resolución, en una esfera moral superior. El príncipe de Dinamarca no es un simple vengador. Su fuerza como principal protagonista del drama no reside en sus vacilaciones y su procrastinación; si solamente se atendiera a sus procedimientos dilatorios lo único que sobresaldría sería su debilidad; sin embargo, desde otra perspectiva su fortaleza y su atractivo están más emparentados con el sentido del sufrimiento religioso. "El héroe estético es grande por su victoria, el héroe religioso, por el sufrimiento. Es muy cierto que el héroe trágico sufre también, pero de tal modo que, al mismo tiempo, su triunfo es extraordinario. Eso es lo que edifica al espectador, mientras llora sobre el moribundo" (SKS 6, 420). El héroe religioso, por el contrario, se asume como víctima sacrificial ante el aparente sinsentido de sus padecimientos. Los disfraces de Hamlet, su aparente locura, su ingenio e ironía, su alegría mordaz, ocultan el sagrado secreto jurado al espectro de su padre y, al mismo tiempo, ocultan el alma abatida de un sufriente que observa cómo la realidad ha perdido su fundamento moral. Este es el sentido profundo de la melancolía y su conexión con la ironía. ${ }^{19}$

${ }^{18}$ La mayoría de los estudios sobre Kierkegaard y Shakespeare se centran en las referencias contenidas a Hamlet en el apéndice de Etapas en el camino de la vida. Puede verse, por ejemplo, Rougemont (1953), Kearney (2014), Lisi (2015). ${ }^{19}$ En su estudio sobre la ironía, Avanessian afirma que "nadie ha examinado el sustrato melancólico de la ironía más a fondo y con más detalle que Kierkegaard, que reformula los topos tradicionales de melancolía bajo los títulos desesperación y tristeza (Avanessian, 2015: 83). 


\section{Conclusión}

La fascinación de Kierkegaard por la obra de Shakespeare es entendible si se toma en cuenta el interés profundo del filósofo danés por el uso de la ironía, no simplemente como un recurso literario, sino como una forma de ponderar la existencia. Esto es lo que concluye en Sobre el concepto de la ironía al sostener que, en buena medida, lo que se afirma de la ironía dominada respecto del poeta y su poesía, puede aplicarse también a la importancia de la ironía en la existencia ordinaria de cualquier individuo; en esto consiste la validez universal de la ironía. Si bien una persona puede carecer del genio poético y no estar en condiciones de producir un poema digno de ese nombre, no obstante, cualquier persona puede servirse de la ironía como guía ya que, "una vez que la ironía ha sido dominada, su función es de extrema importancia para que la vida personal obtenga salud y verdad" (SKS 1, 356). La ironía disciplina y amonesta, limita, termina y restringe, libera de la trampa de pretender, a toda costa, poseer una seguridad ante la vida, o de doblegarnos ante los ídolos encerrados en las teorías filosóficas, sociológicas, psicológicas, económicas o políticas. Para Andrew Burgess, este final con que Kierkegaard cierra su disertación universitaria ejerce una poderosa influencia en todo el libro en su conjunto, de forma que el lector puede volver su mirada y comprender la ironía con una diferente luz, "ya no se trata solamente de un tratado histórico o filosófico; por el contrario, se lee ahora como un llamamiento a una forma particular de vida moral" (Burgess, 2001: 154).

Kierkegaard afirma que "aquello que la duda es para la ciencia, la ironía es para la vida personal" (SKS 1,355), la necesaria tensión que permite desconfiar de lo conseguido, para poder rectificar, replantear, avanzar, y volver nuevamente a poner en tela de juicio lo conseguido. A partir de esta similitud entre la duda y la ironía puede hacerse una paráfrasis, mutatis mutandis, del prólogo de Temor 
y temblor, el cual quedaría así: "Como en un periodo de ofertas y descuentos, nuestra época ha emprendido una oferta de liquidación sobre el fundamento de nuestra existencia, ya no es necesario angustiarse por ella, dudar de su conceptualización o ironizar las actitudes llenas de falsa presunción. Hoy en día ese fundamento se puede comprar a un precio tan bajo que puede preguntarse si aquellos que lo venden ofrecen un producto genuino. En cambio, para Sócrates era distinto, se consideraba ignorante y veía con recelo las respuestas ofrecidas por los demás; consideraba la ironía como un camino por el que había que transitar toda la vida, como una tarea que no termina, pues esa tarea no se cumple en cuestión de días o semanas. Aquel viejo luchador recordaba, hacia el final de su vida, la frecuente necesidad de ironizar que disciplinó su juventud, o la angustia y temblor que lo acompañaron en su madurez, enfrentando las tentaciones de una concepción trivial de la existencia. No había cedido ante los recelos de la egolatría, la seguridad mundana, ni tampoco a las insinuaciones de la compasión simpática”. Esta ironía existencial que Kierkegaard observó en Sócrates como filósofo también puede observarse en Hamlet como ironía dominada en el ámbito de la creación artística.

\section{Bibliografía}

Andersen, Hans Christian, 2004, Kun en Spillemand. Original Roman itre Dele, Det Danske Sprog-ogLitteraturselskab, Copenhagen.

Avanessian, Armen, 2015, Irony and the Logic of Modernity, Nils F. Schott (trans.), De Gruyter, Boston.

Binetti, María J., 2015, El idealismo en Kierkegaard, Universidad Iberoamericana, México. 
Bloom, Harold, 2011, Anatomía de la influencia. La literatura como modo de vida, Damià Alou (trad.), Taurus, México.

, 1991, Ruin the Sacred Truths. Poetry and Belif, Harvard University Press, Massachusetts.

Bose, Siddhartha, 2015, Back and Forth. The Grotesque in the Play of Romantic Irony, Cambridge Scholars Publishing, Newcastel, UK.

Burgess, Andrew J., 2001, "The Upbuilding in the Irony of Kierkegaard's The Concept of Irony", en International Kierkegaard Commentary. The Concept of Irony, Perkins, Robert L. (ed.), Mercer University Press, Macon, Georgia, pp. 141-160.

De Grazia, Margreta, 2001, "Shakespeare and the craft of language", en The Cambridge Companion to Shakespeare, De Grazia (ed.), Cambridge University Press, Reino Unido.

Garber, Frederick, 1988, Romantic Irony, John Benjamins Publishing Company, Amsterdam.

Greenblatt, Stephen, 2001, Hamlet in Purgatory, Princeton University Press, Nueva Jersey.

Goethe, Johann Wolfgang, 1951, Goethes Werke in ZweiBänden, Band 1, Die Berland-Buch-Klassiker, Salzburg.

, 1968, Obras completas, t. II, Rafael Cansinos Asséns (trad.), Aguilar, México.

Hegel, G. W. F, 1985, Lecciones sobre la historia de la filosofía, vol. 3, Wenceslao Roces (trad.), Fondo de Cultura Económica, México.

Houe, Poul, 2016, "The Best to be had is the Expectation of Pleasure: The Outlook of An-Other Hans Christian Andersen, or of Søren Kierkegaard's Other?”, Estudios Kierkegaardianos. Revista de Filosofía, núm. 2, pp. 113-183.

Kierkegaard, Søren, (1997-2013), KierkegaardsSkrifter (SKS), 55 volúmenes, Niels Jørgen Cappelørn, Joakim Garff, Johnny 
Kondrup, Alastair McKinnon y Fin Hauberg Mortensen (eds.), Søren Kierkegaard Forskningscenteretved Københavns Universitet, Gad Publishers, Copenhague.

, 2006, O lo uno o lo otro. Un fragmento de vida I, Begonya Saez Tajafuerce y Darío Gonzalez (trad.), Trotta, Madrid.

, 1988, Stages on Life's Way, Howard Hong and Edna Hong (trad.), Princeton University Press, Nueva Jersey.

, 2012, La época presente, Manfred Svensson (trad.), Trotta, Madrid.

, 2016, ¡Un momento, Señor Andersen!, Nassim Bravo (trad.), Estudios Kierkegaardianos. Revista de Filosofía, núm. 2, 2016, pp. 53-60.

Kearney, Richard, 2004, "Kierkegaard on Hamlet: Between Art and Religion", en The New Kierkegaard, Jegstrup Elsebet (ed.), Indiana University Press, Bloomington, pp. 224-242.

Lisi, Leonardo F., 2015, "Hamlet: The Impossibility of Tragedy / The Tragedy of Impossibility”, en Kierkegaard's Literary Figures and Motifs, t. II, Katalin Nun and Jon Stewart (eds.), Ashgate, Surrey, pp. 13-38.

Minden, Michael, 1997, The German Bildungsroman. Incest and Inheritance, Cambridge University Press, Reino Unido.

Platón, 2010, Menón, Francisco J. Olivieri (trad.), Gredos, Madrid.

Poole, Roger, 1993, Kierkegaard. The Indirect Communication, University Press of Virginia, Charlottesville.

Reid, Jeffrey, 2014, The Anti-Romantic. Hegel Against Ironic Romanticism, Bloomsbury, London.

Rougemont, Denis de, 1953, "Kierkegaard und Hamlet", en Der Monat, vol. 5, núm. 56, pp. 115-124. 
Ruoff, James E., 1968, "Kierkegaard and Shakespeare", Comparative Literature, vol. 20, núm. 4, pp. 343-354.

Shakespeare, William, 2003, The Tragedy of Hamlet Prince of Danmark, Burton Raffel (anotada por), Harold Bloom (ensayo), Yale University Press, New Haven. , 2015, Hamlet, Manuel A. Conejero y Jenaro Telens (trad.), Ediciones Cátedra/Fundación Shakespeare de España, Madrid. , 1798, Hamlet, Inarco Celenio y Leandro Fernández de Moratín (trad.), O. Villalpando, Madrid.

Schiller, Friedrich, 2005, Kallias. Cartas sobre educación estética del hombre, Jaime Feijóo (trad.), Anthropos/Ministerio de Educación y Ciencia, Barcelona.

Schlegel, Friedrich, 2009, Fragmentos, Pere Pajerols (trad.), Marbot ediciones, Barcelona.

Soderquist, K. Brian, 2013, The Isolated Self. Truth and Untruth in Soren Kierkegaard's On the Concept of Irony, Museum Tusculanu Press, Copenhagen.

Stewart, Jon, 2017, Søren Kierkegaard: Subjetividad, ironia y la crisis de la modernidad, Azucena Palavicini (trad.), Universidad Iberoamericana, México.

Summers, Richard M., 2001, “'Controlled Irony' and the Emergence of the Self in Kierkegaard's Dissertation", en International Kierkegaard Commentary. The Concept of Irony, Perkins, Robert (ed.), Mercer University Press, Georgia, pp. 289-316. 